\title{
Contribution to the Characterization of Bacillus megaterium
}

\author{
A. CANDELI, A. De BARTOlOMEO, V. MASTRANDREA, and F. TROTTA \\ Istituto di Igiene della Facoltà di Scienze MM.FF.NN. della Università degli Studi di Perugia, 06100 \\ Perugia, Italy
}

\begin{abstract}
A study of the cellular and colonial morphologies, the deoxyribonucleic acid (DNA) base composition, the degree of lysis by lysozyme, and some fundamental biochemical reactions was carried out on 23 strains previously identified as members of Bacillus megaterium. Included among these was NCTC 10342, the neotype strain of $B$. megaterium. The results showed that, primarily on the basis of their biochemical reactions, two of the strains belong to $B$. cereus, two belong to $B$. subtilis, and 19 belong to $B$. megaterium. The first two strains mentioned above clearly differed from $B$. megaterium strains with respect to their DNA base composition ( 33.2 and $34.3 \mathrm{~mol} \%$ guanine plus cytosine [G+C]), their lysis by lysozyme (5.6 and 6.6\%), and the morphology of their macro- and microcolonies. These properties were not helpful in differentiating the other two strains from the $B$. megaterium strains, for the two strains showed high $\mathrm{G}+\mathrm{C}$ values $(45.9$ and $47.4 \mathrm{~mol} \%)$ and high values of lysis by lysozyme, (92.9 and $96.7 \%)$. The 19 remaining strains, confirmed as members of $B$. megaterium, had $\mathrm{G}+\mathrm{C}$ contents which varied from 37.3 to $43.0 \mathrm{~mol} \%$ and lysis percentages which varied from 67.0 to 94.9. For these strains, a significant $(P<0.05)$ correlation was found between the DNA base composition and lysis by lysozyme. Three biogroups were established on the basis of the biochemical reactions of the 19 strains. These biogroups are similar to the "aggregate" and the "intermediate" strains of B. megaterium established by Gordon et al.
\end{abstract}

In a previous paper, Candeli et al. (6) pointed out that three characteristics (colony shape, susceptibility to lysozyme, and deoxyribonucleic acid [DNA] base composition) were closely related to each other and were suitable for dividing seven of the Bacillus species studied into two groups. In the first group (B. subtilis, B. pumilus, $B$. licheniformis, and $B$. firmus), the rhizoid shape of the colonies was linked to a high degree of susceptibility to lysozyme and to a mean guanine-plus-cytosine $(\mathrm{G}+\mathrm{C})$ content of the DNA of $44.15 \pm 1.64 \mathrm{~mol} \%$. In the second group (B. cereus, B. cereus subsp. mycoides, B. anthracis, and $B$. thuringiensis), the "medusa head" shape of the colonies was related to a very low susceptibility to lysozyme and to a mean $\mathrm{G}+\mathrm{C}$ value of $33.65 \pm 0.59 \mathrm{~mol} \%$. This taxonomic arrangement coincided (with few strain exceptions) with that presented for these species in Bergey's Manual (7) and based mainly on cell morphology and biochemical reactions. One exception involved the two strains studied which bore the name B. megaterium; one (ATCC 7481) was included in the first group, and the other (NCTC 10342, the neotype strain of $B$. megaterium) belonged to neither of the two groups, although according to Bergey's Manual (7) it should belong to the $B$. cereus-B. anthracis-B. thuringiensis group. On the other hand, Bonde and Jackson (3) concluded that $B$. megaterium should be placed near $B$. subtilis, B. pumilus, and $B$. licheniformis (group $C$ of these authors), particularly because of its DNA base composition.

Our observations, based on only two strains of $B$. megaterium, were similar to those made by Baumann-Grace and Tomcsik (2) many years ago and by Gordon et al. (9) rather recently. According to these two groups of authors, who used different techniques, $B$. megaterium is composed of two merging aggregates of strains which, according to Gordon et al. (9), could not be clearly separated because of intermediate strains which "blurred the division of the two aggregates."

The intent of the study reported here was to determine whether these $B$. megaterium strain clusters could be better defined and segregated on the basis of cellular and colonial morphology, susceptibility to lysozyme and sodium lauryl sulfate, DNA base composition, and biochemical reactions.

\section{MATERIALS AND METHODS}

Bacterial strains. Twenty-three strains of B. megaterium (Table 1) were tested. All of the strains were maintained in the collection of our institute both as agar stab cultures (1.0\% agar in nutrient broth [Difco 
TABLE 1. Strains labeled as B. megaterium and used in this study ${ }^{a}$

\begin{tabular}{|c|c|c|}
\hline Laboratory strain no. & Other strain designation & Source \\
\hline IIU $\mathrm{Pg} 128$ & IIU $\mathrm{Pg} 128$ & Istituto di Igiene Univ., Padova, Italy \\
\hline IIU Pg 565 & IIU Pg 565 & $\begin{array}{l}\text { Istituto Microbiologia Univ., Rome, Italy } \leftarrow \text { Institut Pas- } \\
\text { teur, Paris, France }\end{array}$ \\
\hline IIU Pg 571 & ISVT SCLAVO & ISVT SCLAVO \\
\hline IIU Pg 619 & ISM $65 / 15$ & ISM \\
\hline IIU Pg 620 & NCTC 10342 & NCTC \\
\hline IIU Pg 621 & ATCC 7481 & Istituto Superiore Sanità, Rome, Italy \\
\hline IIU Pg 659 & NCTC 5635 & NCTC \\
\hline IIU Pg 704 & NCIB 8508 & NCIB \\
\hline IIU Pg 711 & CCM 1462 & $\mathrm{CCM}$ \\
\hline IIU Pg 712 & CCM 1621 & CCM \\
\hline IIU Pg 713 & CCM 2037 & CCM \\
\hline IIU Pg 714 & CCM 391 & CCM \\
\hline IIU Pg 715 & CCM 1711 & CCM \\
\hline IIU Pg 716 & CCM 2036 & ( \\
\hline IIU Pg 718 & ATCC 99 & $\begin{array}{l}\text { R. E. Gordon, Institute of Microbiology, Rutgers Univer- } \\
\text { sity, New Brunswick, N.J. }\end{array}$ \\
\hline IIU Pg 719 & ATCC 8011 & New Jersey \\
\hline IIU Pg 720 & ATCC 14945 & New Jersey \\
\hline IIU Pg 721 & ATCC 14946 & New Jersey \\
\hline IIU $\mathrm{Pg} 750$ & NCTC 5637 & NCTC \\
\hline IIU Pg 751 & NCTC 6005 & NCTC \\
\hline IIU Pg 752 & NCTC 6094 & NCTC \\
\hline IIU Pg 753 & NCTC 7581 & NCTC \\
\hline IIU Pg 754 & NCTC 9848 & NCTC \\
\hline
\end{tabular}

${ }^{a}$ Abbreviations: ATCC, American Type Culture Collection, Rockville, Md.; CCM, Czechoslovak Collection of Microorganisms, 662 Brno, tr. Obrancu miru 10, Czechoslovakia; IIU Pg, Istituto di Igiene, Facoltà di Scienze, Università, Perugia, Italy; ISM, Istituto Sieroterapico Milanese "S. Belfanti," Milan, Italy; ISVT SCLAVO, Istituto Sieroterapico Vaccinogeno Toscano "SCLAVO," Siena, Italy; NCIB, National Collection of Industrial Bacteria, Aberdeen, Scotland; NCTC, National Collection of Type Cultures, Central Public Health Laboratory, London NW9 5HT, England.

Laboratories]) and as pure spore preparations in sealed vials.

Methods: The morphology and Gram reactions of the cells were determined by using 2- to 8-day-old cultures on soil extract agar slants (9).

The characteristics of nutrient agar colonies were observed both macroscopically in petri dishes and microscopically by the slide culture technique (5).

The biochemical reactions of the strains were studied by the techniques of Buttiaux et al. (4) with the exception of the egg yolk reaction, the citrate utilization test, and the phenylalanine deamination test, which were taken from Gordon et al. (9).

Lysis of microbial cells was studied by the techniques of Mastrandrea et al. (12). The lytic agents used were lysozyme chloride (Societá Prodotti Antibiotici, Milan, Italy) at a final concentration of 40 $\mu \mathrm{g} / \mathrm{ml}\left(1 \mathrm{~h}\right.$ at $\left.37^{\circ} \mathrm{C}\right)$ and sodium lauryl sulfate (BDH Italia, Milan) at a final concentration of $2 \%$ (wt/vol) $\left(10 \mathrm{~min}\right.$ at $\left.60^{\circ} \mathrm{C}\right)$. The percentage of lysis was calculated by the formula reported below; the optical density (OD) of the bacterial cells suspended in physiological solution was measured before $\left(O D_{c}\right)$ and after $\left(O D_{t}\right)$ the action of the lytic agent at a wavelength of $520 \mathrm{~nm}$, using a Pye Unicam spectrophotometer, model SP 1800:

$$
\% \text { lysis }=\frac{O D_{c}-O D_{t}}{O D_{c}} \times 100 .
$$

The DNA base composition was determined by the melting temperature technique after DNA had been isolated from the vegetative cells (8-h-old agar culture) by the Marmur procedure (10). Cells which were resistant to both lysozyme and sodium lauryl sulfate were mechanically disintegrated in a Mickle tissue disintegrator. For each sample of DNA, at least three melting temperature determinations were carried out spectrophotometrically. The standard errors, calculated within each group of measurements, ranged from a minimum of \pm 0.03 to a maximum of \pm 0.22 . The $\mathrm{G}+\mathrm{C}$ content was calculated from the average of the experimental values of the melting temperature.

\section{RESULTS}

Some of the characteristics determined were common to all of the strains studied, whereas others were not.

The biochemical reactions common to the 23 tested strains were: production of catalase and gelatinase, hydrolysis of starch, acid production from glucose, and decomposition of casein. Moreover, all of the strains were resistant to lysis by sodium lauryl sulfate.

The DNA base composition, the percentage of lysis by lysozyme, some biochemical reactions, 
and the morphology of cells and colonies varied with the strains. The data relating to these properties, with the exception of morphology, are presented in Table 2 and may be summarized as follows.

Strains 565 and 571 showed the lowest G+C values of DNA ( 33.2 and $34.3 \mathrm{~mol} \%$, respectively) and an almost complete resistance to lysozyme. They grew anaerobically and were positive with respect to the following: Voges-Proskauer test, egg yolk reaction, reduction of nitrate to nitrite, urease production, and utilization of citrate as a sole source of carbon. These strains did not produce acid from arabinose, xylose, or mannitol and did not deaminate phenylalanine.

Strains 128 and 621 showed the highest $\mathrm{G}+\mathrm{C}$ values (45.9 and $47.4 \mathrm{~mol} \%$, respectively), were very highly susceptible to lysozyme ( $>90 \%$ lysis), and gave positive results in the following: VogesProskauer reaction; acid production from arabinose, xylose, and mannitol; urease production; and utilization of citrate as a sole source of carbon. They did not grow anaerobically or deaminate phenylalanine, and they gave a negative egg yolk reaction. Strain 621 reduced nitrate to nitrite, whereas strain 128 did not.

The remaining 19 strains had $\mathrm{G}+\mathrm{C}$ values which ranged from 37.3 to $43.0 \mathrm{~mol} \%$ and percentages of lysis by lysozyme which ranged from 67.0 to 94.9 . The biochemical reactions in which all the strains were positive are cited in the footnote to Table 2 . They did not grow anaerobically, and they were negative with respect to the Voges-Proskauer test and the egg yolk reaction. Variable results were obtained with the following: acid production from arabinose, xylose, and mannitol; urease production; reduction of nitrate to nitrite; and deamination of phenylalanine.

The morphology of the cells and of the spores essentially corresponded with the description given by Gordon et al. (9) and in Bergey's Manual (7) for $B$. megaterium. The cells were rod shaped and measured 1.2 to 1.5 by 2.5 to $5.0 \mu \mathrm{m}$ (two strains [128 and 621] measured 0.6 to 0.8 by 2.5 to $5.0 \mu \mathrm{m}$ ). Ellipsoidal as well as round spores occurred; the spores were centrally or paracentrally located in the cells. In two strains (620 and 659) the spores did not appear after 8 days of incubation on soil extract agar culture. It should be noted that strain $620 \quad(=$ NCTC 10342 ) is the neotype strain of $B$. megaterium (7). As shown in Fig. 1 through 6, three types of colonies were observed. "Medusa head" colonies were seen in both macro- and microcolonies of strains 565 (Fig. 1 and 2) and 571. Rhizoid macrocolonies observed on an agar surface corresponded to "star"-shaped microcolonies (formed by short, straight chains of rods) on slide cul- tures of strains 754, 128 (Fig. 3 and 4), and 621. For the remaining 18 strains, the macrocolonies were similar to those described for the rhizoid strains (except that the edges were lobate instead of rhizoid [Fig. 5]), and the microcolonies showed the structure of the star-shaped microcolonies, but the chains of rods were wavy instead of straight (Fig. 6).

\section{DISCUSSION}

Because of the very low $\mathrm{G}+\mathrm{C}$ contents of their DNAs, their very low susceptibility to lysozyme, the morphology of their colonies, and some of their biochemical reactions (especially their growth under anaerobic conditions and their positive Voges-Proskauer tests and egg yolk reactions), strains 565 and 571 are not strains of $B$. megaterium but rather of $B$. cereus $(6,7,9)$. Nevertheless, data obtained by Somerville and Jones (14) indicate that $B$. megaterium includes strains with a wide range of relatedness, so that it is possible that some of them may be closer than others in their relationship to $B$. cereus; for example, these authors showed 75\% DNA-DNA homology between strain $64 a$ of $B$. megaterium and strain $\mathrm{T}$ of $B$. cereus.

On the other hand, because of the high $\mathrm{G}+\mathrm{C}$ contents of their DNAs, their high susceptibility to lysozyme, and some of their biochemical properties (especially positive Voges-Proskauer tests), strains 128 and 621 should be considered as members of $B$. subtilis. However, it should be pointed out that some of the biochemical reactions which we found for strain 621 (= ATCC 7841) did not agree with those reported by Gordon et al. (9) for this same strain. According to these authors, the Voges-Proskauer test and the reduction of nitrate to nitrite should be negative instead of positive and the phenylalanine deamination should be positive instead of negative for strain 621. Thus, it would appear that the various collections containing this strain do not have the same cultures and that some mixup might have occurred.

The remaining strains possessed biochemical propertiès which were in agreement with those of $B$. megaterium $(7,9)$. Although the salient biochemical reactions of $B$. megaterium were common to these 19 strains, some biochemical reactions were variable. Ten of these strains (659, 711, 712, 713,714, 715, 750,751, 752, and 753) possessed characters in agreement with those described by Gordon et al. (9) for a group of strains called the "first aggregate." Three strains $(718,719$, and 720$)$ showed the biochemical reactions of the "second aggregate" of these authors, who examined the same three strains tested here, and six $(619,620,704,716,721$, and 


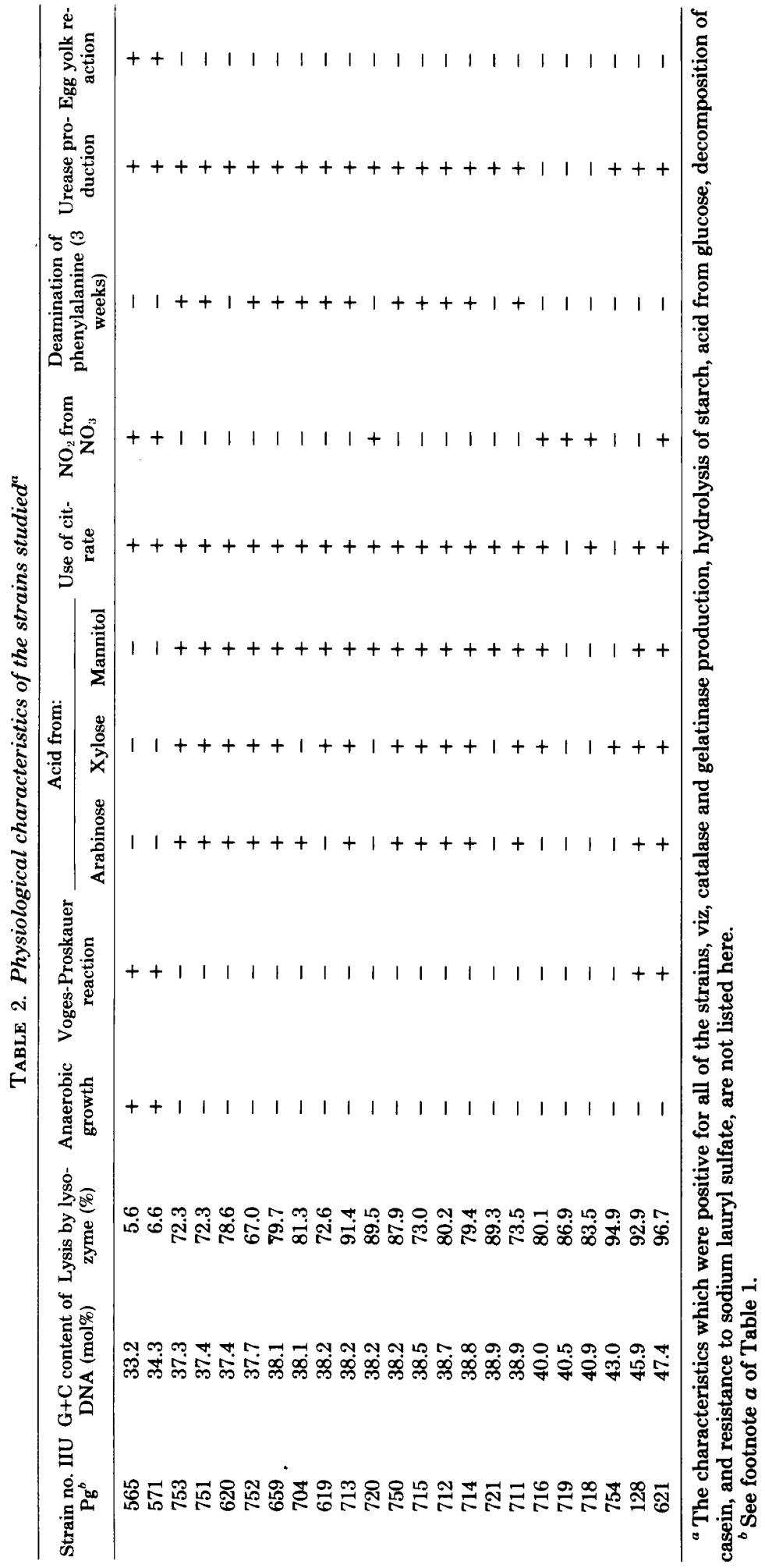


754) showed characteristics of both aggregates and appeared to correspond to those strains called "intermediate" by Gordon et al. (9).

It is interesting that, for the 19 strains of $B$. megaterium, high values of lysis by lysozyme corresponded with high $\mathrm{G}+\mathrm{C}$ values. It was further determined that for these strains there was a significant correlation $(P<0.05)$ between lysis by lysozyme and DNA base composition. These data are in line with the results obtained by Candeli et al. (6) in a study carried out on

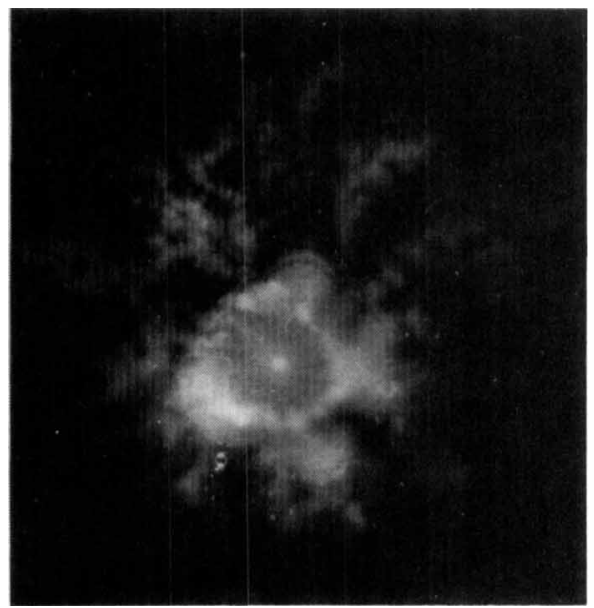

Fig. 1. Macrocolony of strain IIU Pg 565. different Bacillus species. Moreover, the lysozyme lysis values allowed a sharp division between the $19 \mathrm{~B}$. megaterium strains and the 2 strains which were identified as members of $B$. cereus. However these values were of no assistance in differentiating the $B$. megaterium strains from the two strains with biochemical properties of $B$. subtilis. The data concerning lysis by lysozyme corroborated the observations made by Gordon (8) in a paper dealing with the taxonomy of the genus Bacillus.

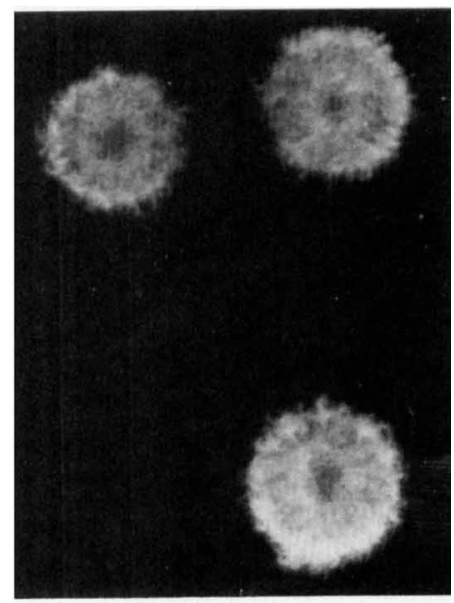

Fig. 3. Macrocolony of strain IIU Pg 128.

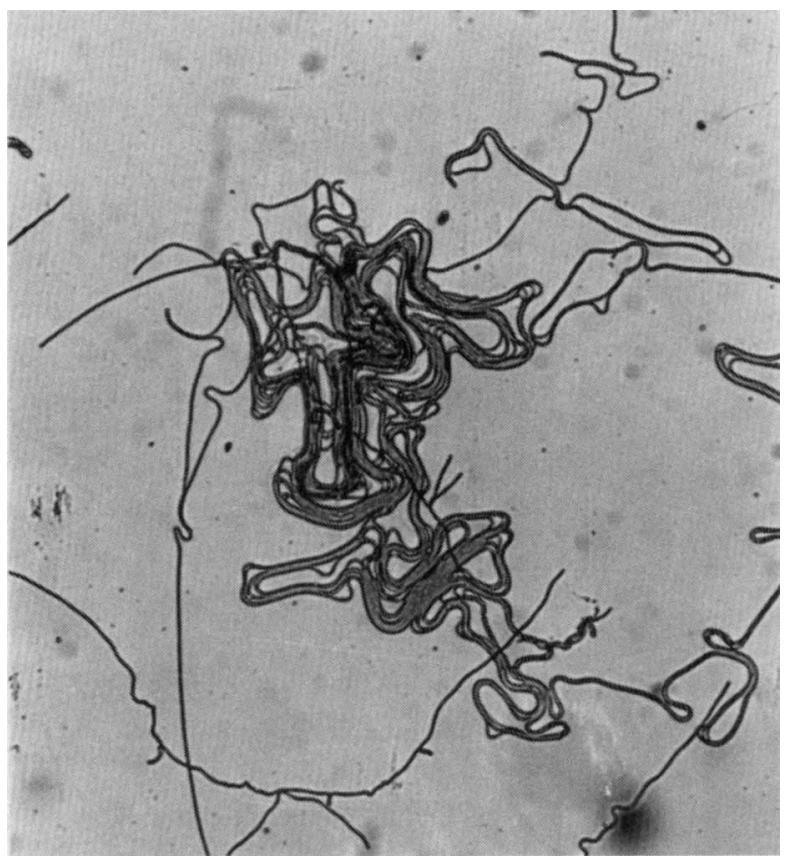

FIG. 2. Microcolony of strain IIU Pg 565. $\times 400$. 
The majority of the $19 \mathrm{~B}$. megaterium strains had $\mathrm{G}+\mathrm{C}$ values which ranged from 37.3 to 38.9 mol\%; 4 strains $(716,718,719$, and 754$)$ had higher values ( 40.0 to $43.0 \mathrm{~mol} \%)$. Comparing these data with the data obtained in our previous work (6) for the species B. cereus (32.5 to 33.6 $\mathrm{mol} \% \mathrm{G}+\mathrm{C}$ ) and B. subtilis (42.7 to $44.2 \mathrm{~mol} \%$ $\mathrm{G}+\mathrm{C}$ ), it is possible to point out that the $\mathrm{G}+\mathrm{C}$ values of $B$. megaterium are sharply distinct from those found for the strains belonging to the species $B$. cereus examined in the previous work (6) and also for the two strains (565 and 571) examined here and considered to be members of $B$. cereus. On the contrary, the $\mathrm{G}+\mathrm{C}$ values of the $19 \mathrm{~B}$. megaterium strains show no sharp division from those of the $B$. subtilis strains previously examined (6) and from those of the two strains tested here (128 and 621) and considered to be strains of $B$. subtilis.

Therefore B. megaterium and B. subtilis, because of their DNA base composition and their degree of lysis by lysozyme, appear to blend into

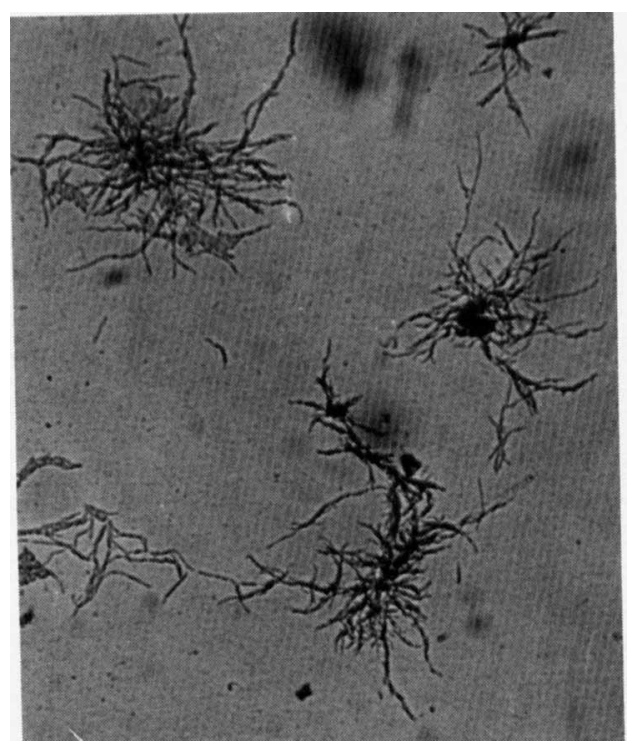

FIG. 4. Microcolony of strain IIU Pg 128. ×100.



FIG. 5. Macrocolony of strain IIU Pg 704.

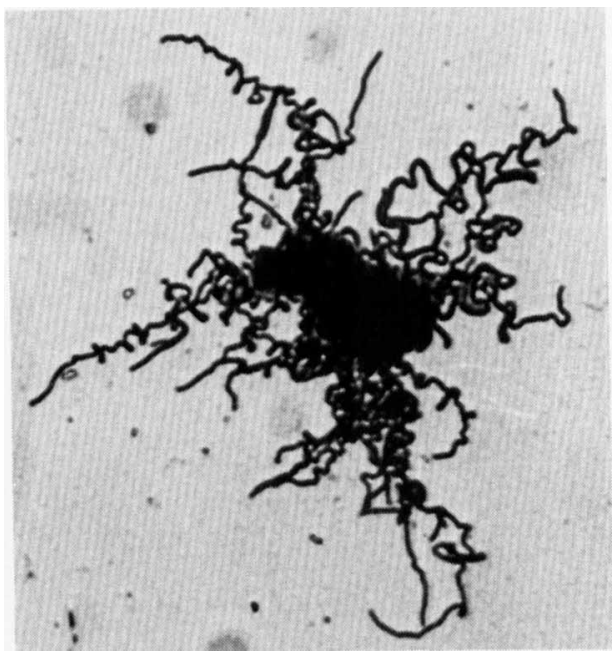

Fig. 6. Microcolony of strain IIU Pg 704. $\times 100$.

each other, strain 754 acting like a bridge between them. Nevertheless, on the basis of other characteristics, e.g., DNA homology (13) and electrophoretic types of enzymes (1), these two species should be considered very distant from each other.

\section{ACKNOWLEDGMENTS}

We are grateful to Ruth E. Gordon for providing strains and for reviewing the manuscript.

\section{REPRINT REQUESTS}

Address reprint requests to: Professor A. Candeli, Istituto di Igiene della Facoltà di Scienze MM.FF.NN., Università degli Studi di Perugia, Via del Giochetto, 06100 Perugia, Italy.

\section{LITERATURE CITED}

1. Baptist, J. N., M. Mandel, and R. L. Gherna. 1978. Comparative zone electrophoresis of enzymes in the genus Bacillus. Int. J. Syst. Bacteriol. 28:229-244.

2. Baumann-Grace, J. B., and J. Tomcsik. 1957. Lysozymempfindlichkeit der Spezies B. megaterium. Experientia 13:148-150.

3. Bonde, G. J., and D. K. Jackson. 1971. DNA-base ratios of Bacillus strains related to numerical and classical taxonomy. Proc. Soc. Gen. Microbiol. 69:vii-viii.

4. Buttiaux, R., H. Beerens, and A. Tacquet. 1974. Manuel de techniques bactériologiques, 4th ed. Flammarion Medicine-Sciences, Paris.

5. Candeli, A., and V. Mastrandrea. 1964. Ricerche sulle fasi dissociative del $B$. anthracis. Boll. Ist. Sieroter. Milan. 43:45-46.

6. Candeli, A., V. Mastrandrea, G. Cenci, and A. De Bartolomeo. 1978. Sensitivity to lytic agents and DNA base composition of several aerobic spore-bearing bacilli. Zentralbl. Bakteriol. Parasitenkd. Infektionskr. Hyg. Abt. 2 133:250-260.

7. Gibson, T., and R. E. Gordon, 1974. Genus I. Bacillus Cohn 1872; nom. gen. cons. Nomencl. Comm. Intern. Soc. Microbiol. 1937; Opin. A. Jud. Comm. 1955, p. 529-550. In R. E. Buchanan and N. E. Gibbons (ed.), Bergey's manual of determinative bacteriology, 8 th ed. The Williams \& Wilkins Co., Baltimore.

8. Gordon, R. E. 1975. Some taxonomic observations on the 
genus Bacillus. Biological regulation of vectors. The saprophytic and aerobic bacteria and fungi. A conference report, Tidewater Inn, Easton, Md., October 6 to 8. DHEW publication no. (NIH) 77-1180, p. 67-82 Department of Health, Education and Welfare, Washington, D.C

9. Gordon, R. E., W. C. Haynes, and C. H. N. Pang. 1973 The genus Bacillus. Agriculture handbook no. 427. U.S. Department of Agriculture, Washington, D.C.

10. Marmur, J. 1961. A procedure for the isolation of deoxyribonucleic acid from microorganisms. J. Mol. Biol. 3: 208-218.
11. Marmur, J., and P. Doty. 1962. Determination of the base composition of deoxyribonucleic acid from its thermal denaturation temperature. J. Mol. Biol. 6:109-113.

12. Mastrandrea, V., A. Candeli, A. De Bartolomeo, and G. Cenci. 1975. Lisi cellulare e fasi dissociative del genere Bacillus. Boll. Ist. Sieroter. Milan. 54:367-377.

13. Seki, T., C. Chung, H. Mikami, and Y. Oshima. 1978. Deoxyribonucleic acid homology and taxonomy of the genus Bacillus. Int. J. Syst. Bacteriol. 28:182-189.

14. Somerville, H. S., and M. L. Jones. 1972. DNA competition studies within the Bacillus cereus group of bacilli. J. Gen. Microbiol. 73:257-265. 